4. Bob C, ed. The International Struggle for New Human Rights. Pittsburgh: University of Pennsylvania Press, 2008.

5. Swartz L, van der Merwe A, Buckland A, et al. Producing boundary-breaking texts on disability issues: the personal politics of collaboration. Disabil Rehabil. Published Online First: 9 Dec 2011. doi:10.3109/09638288.2011.624248.
6. McDougall K, Swartz L, van der Merwe A. Zip Zip My Brain Harts (Text for Work with Photographs by Angela Buckland). Cape Town: HSRC Press, 2006. http://www. hsrcpress.ac.za/product.php?productid $=2157 \& c a t=5 \& p a g e=1$

7. Swartz L. Able-Bodied: Scenes from a Curious Life. Cape Town: Zebra Press, 2010.

\title{
Poetry and prose
}

\section{Together and waiting}

The people in the waiting room at the hospital cannot help but wonder just what is wrong with everyone else.

The old woman in the borrowed wheelchair.

The man with the bandaged right hand.

The brown child whose mother is crying.

Someone has taped paper flowers to the wall.

A person in a green outfit will come for them soon.

They will learn, one at a time, the names of

The old woman in the borrowed wheelchair.

The man with the bandaged right hand.

The brown child whose mother is crying.

They all just want to be OK,

for the person in the green outfit to tell them so.

Then they can be happy again, happy

to be gone from the waiting room at the hospital.

And they can forget

the colors of the paper flowers taped to the wall

and the names they had learned one at a time.

\section{Daniel Thomas Moran}

Correspondence to Daniel Thomas Moran, 515 Shawmut Ave \#1, Boston, MA 02118, USA; dan@danielthomasmoran.net

Competing interests None.

Provenance and peer review Not commissioned; internally peer reviewed.

Published Online First 6 January 2012

Med Humanit 2012;38:37. doi:10.1136/medhum-2011-010148 